it occurs in a voluntary muscle we speak of it as clonic contraction.

The third case forms a striking contrast to the "inadequate ureter" we have just considered. At the kind request of Dr. Chapman Grigg, Mr. Stabb was good enough to preserve for me a fœtus born at nearly full time with great enlargement of the abdomen due to some abnormal condition of the urinary organs. On dissection it was found that the fœetus had no anus and the rectum ended blindly on the back of the

FIIG. 2.

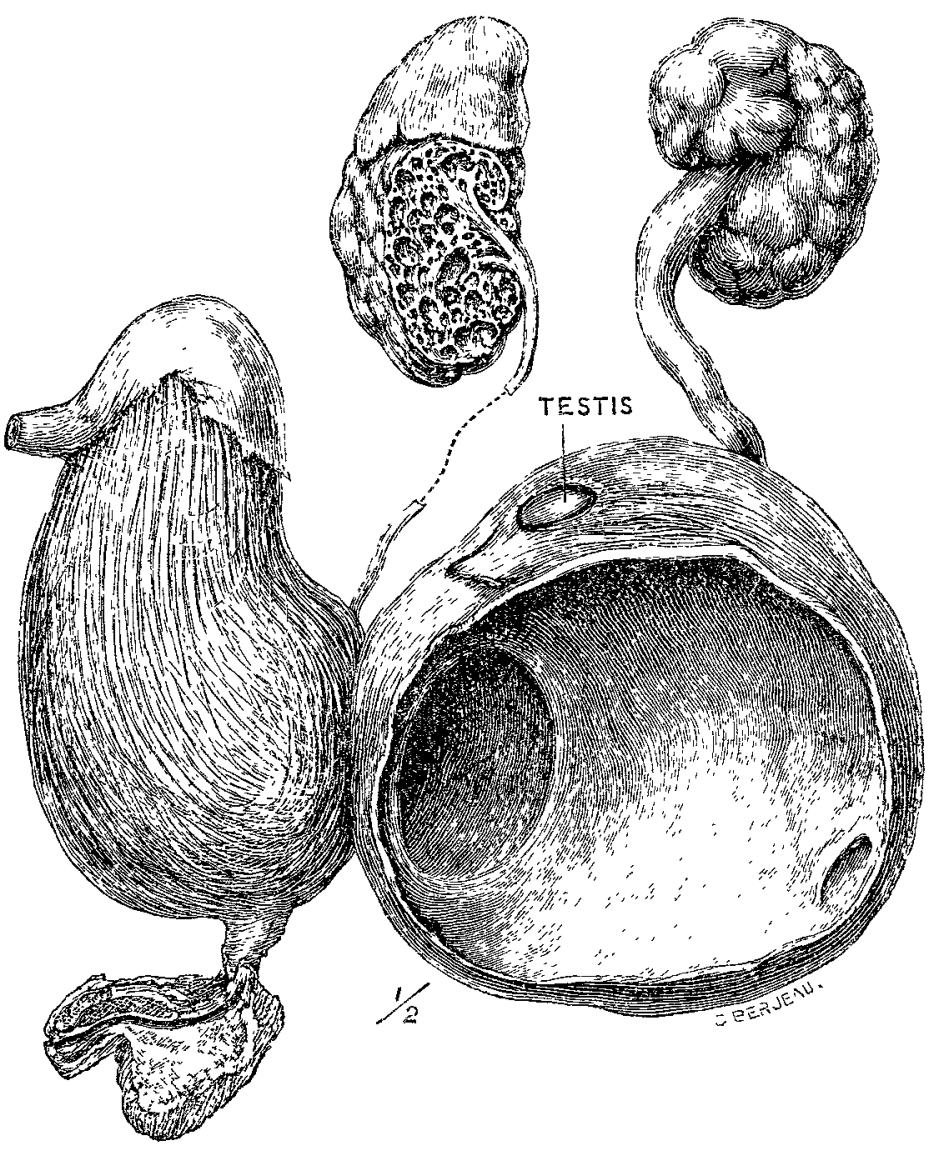

Hypertrophied bladder, dilated ureter, and hydronephrotic and cystic kidneys from a foetus with imperforate urethra.

bladder. The penis and scrotum were normal, but the urethra ended at the bulb; from that point to the bladder it was impervious. The bladder, as shown in Fig. 2, was distended and its walls greatly hypertrophied, the muscular fasciculi standing out as thick strands. Connected with the left side of the bladder is a large sacculus capable of holding 300 c.c. of fluid ; the left ureter opens into this sacculus by a valvular orifice. The ureter itself is dilated throughout as well as the renal pelvis. The sacculus communicates with the resical cavity by an orifice 3 centimetres in cliameter. A careful study of the relations of the sacculus proves that it is an enormous local dilatation of the ureter and as it enlarged it carried on its crest the testis; the spermatic ressels were seen in the fresh condition of the specimen stretched across its wall. The right kidney is a congeries of cysts-an example of the condition known as congenital cystic kidney. The areter is a thin narrow thread.

Although this specimen is devoid of what is commonly called practical interest it has, nevertheless, importance of another kind. First of all, it indicates that many specimens which have been loosely described as bifid bladders were probably of the same character as this. Some specimens described as bifid bladders are due to dilatation of the urachus (allantoic cysts), and others reported as examples of lateral bifidity of the bladder or congenital diverticulum of the bladder were in all probability, as in my specimen, enlargement of the vesical end of the ureter. It is instructive, also, to find a hydronephrotic kidney on one side and congenital cystic kidney on the other. This form of cystic kiåney has long puzzled pathologists. and its association with an imperforate urethra must lead to a reconsideration of some views beld in regard to its causation.

Queen Anne-ztreet, $\mathbf{W}$.

\section{A SUGGESTION FOR INTESTINAL ANASTOMOSIS.}

Bx J. JACKSON CLARKE, M.B. LoND., F.R.C.S. ENG., ASSIS'CAYT-SURGEON TO THE NOR'TH-WEST LONDON HOSPITAL, PATHOLOGIST TO ST. MAKY'S HOSPITAL.

THovgr careful stitching would appear to be the best method of reuniting divided intestine, it is common knowledge that in many cases the condition of the patient is such that any prolonged operation is out of the question, and in such cases some of the many ingenious mechanical devices invented for the purpose have to be called in requisition. In venturing to suggest an addition to the already formidable array of such instruments I naturally feel some diffidence, but I am encouraged by the reflection that, as far as I am aware, the principle of the apparatus to which I would draw attention has not been previously employed. The most ingenious and expeditious mechanical method of instrumental anastomosis is that derised by Murphy, whose "button" has no doubt saved many lives, and some of the successful cases bave been treated at the hospital at which I was trained. I have, however, been called to make necropsies in a few cases in which the issue has been fatal, and in two of them I found that the wall of the gut had sloughed where it lay over the rim of the metal diaphragm which is pressed by a spring against the double layer of bowel. In the instrument which I have devised the pressure is made by indiarubber rings the edges of which are rounded off. In Fig. 1 is shown

FIG. 1.

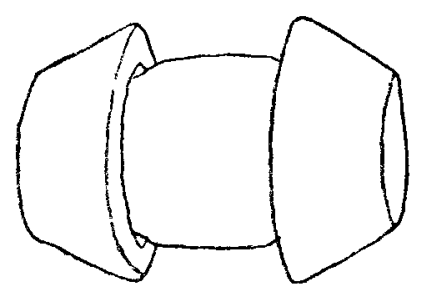

Outline sketch of the bobbin (natural size).

the size of the instrument as designed for small intestine; for large intestine an additional quarter of an inch in diameter could be obtained. Fig. 2 represents the bobbin as seen in section. The chamber AC could be used to contain some mild antiseptic. In the lower part of Fig. 2 the rubber rings are shown with the

\section{Fry. 2.}
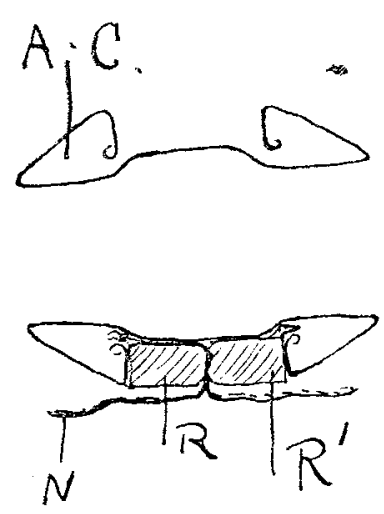

Longitudinal section of the bobbin, the intestine ( $\mathrm{N}$ ), and incia-rubber rings ( $R$ and $k^{\prime}$ ) shown in section below.

bowel in situ. Both have the same diameter as the smaller part of the bobbin-i.e., half an inch. They are cut so that when stretched to the diameter of the barrel of the empty bobbin their depth just brings them flush with the lips of the larger ends of the bobbin. The mesial edges, both inner 
and outer, of the rubber bands are slightly rounded off. One band $(R)$ is half as wide as the barrel, and the other $\left(\mathbf{R}^{\prime}\right)$ is cut obliquely, so that at its outer edge it is in. wider than half the length of the barrel. The mode of making the anastomosis is shown in Fig. 3 . One of the rubber rings

FIG. 3.

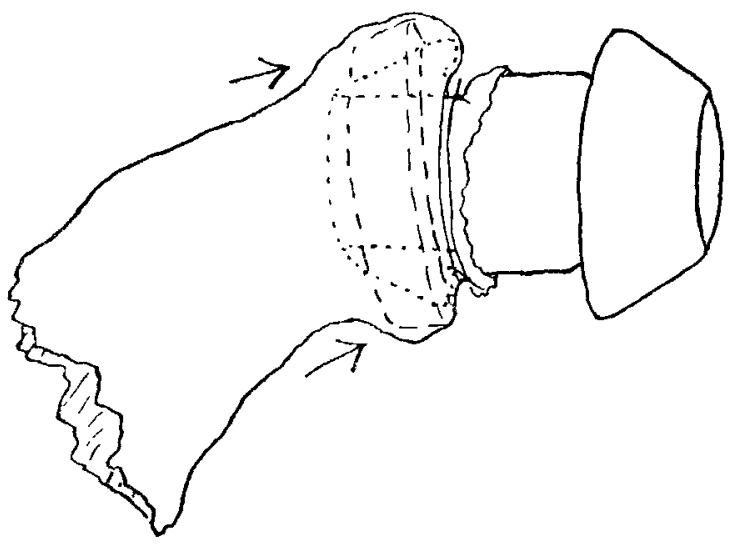

Showing the mode of pusbing the ring into position after the bowel has been secured to the bobbin by a purse-string ligature. Only one ring is shown, although both are pushed on at the sime time.

is lubricated with oil or soap and is inserted into one end of the gut, and then a purse-string stitch is run close to the border of the intestine and securely tied over the narrow neck of the barrel. The other end of the gut is treated in the same way, then the rings are easily pushed (by the fingers of the operator pressing through the gut) over the ends of the bobbin on to the barrel, and thus a secure anastomosis is effected. The redundant part of the mesentery may be drawn into two triangular folds, one on each side of the bowel, and fixed, as shown in Fig. 4.

FIG. 4.

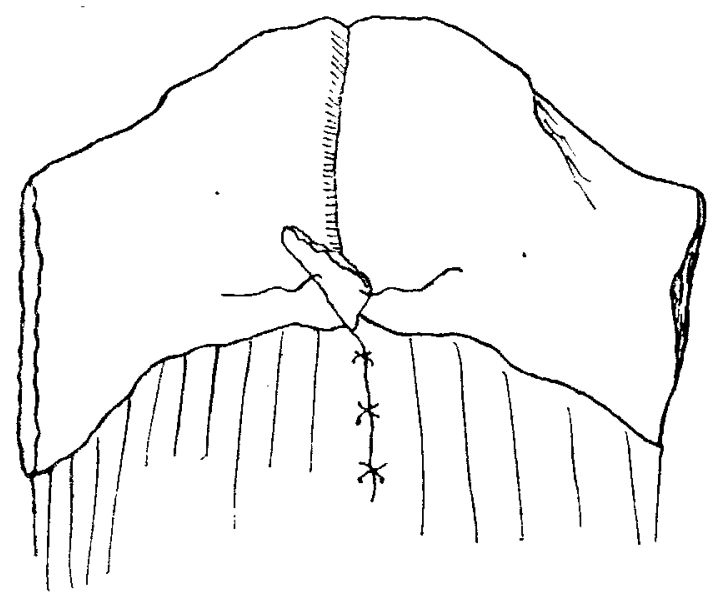

The appearance of the anastomosis when completed.

I have tried the process on both thin atrophic and thick cedematous bowel in the cadaver and found it work well, the anastomosis being effected in six minutes. After the anastomosed bowel had been for some days on the instrument in weak formalin solution the part of the bowel between the rubber tubes was found to be thin and papery, whilst the rest of the bowel was thick and succulent. The slight wedge-shape of the rings would seem to secure sufficient pressure to cause sloughing. I hope soon to acquire the power to test the apparatus on some suitable quadruped. Its advantages would appear to be as follows. It does away with the sharp cutting rim of Murphy's button, it is much lighter (if made of aluminium it would be extremely light), it has a much larger lumen (and thus would cause less obstruction and allow more rest to the bowel), its ends are more tapering, the antiseptic chamber could be used to contain a weak glycerin-gelatin carbolic mixture which by osmosis would keep in check too rapid sloughing at the line of separation, and it is simpler and cheaper. The instrument has been very skilfully made for me by Messrs. Meyer and Meltzer.

old Cavendish-street.

\section{LEUCOCYTH 2 EMIA $\Lambda$ ND IT'S TREATMENT.}

By RICHARD J. COWEN, I.R.C.P., L.R.C.S. IREL.

ON July 1st, 1895, a married woman aged twenty-eight years was brought to me for treatment. In appearance she was exceedingly pale, with dark areolas around the eyes; she seemed to suffer from great difficulty of breathing in walking and much lassitude. She described her ailment and its history as follows. Some two months ago she noticed that she was getting weaker, and her friends were constantly telling her how bad she was looking; her appetite was getting worse every day, and even the sight of food filled her with disgust. She noticed that she had increased difficulty in going upstairs because she "pantcd so much," and even walking on level ground caused her the same trouble. She lost all interest in her daily work and her spirits were very much depressed. She suffered a good deal from pains in the abdomen and she found her waist had increased in size, indeed, so much so that her neighbours congratulated her upon the probability of an accession to her family. About this time she went to see a medical man, and was treated, she believes, with arsenic and iron, but under his treatment she found herself rapidly getting worse. Occasionally she noticed large bruises appearing on her legs and arms and she could not imagine how she got them. Her family history, as far as I could ascertain it, was good, her parents and grandparents being very healtby people. She had two children. She had never suffered from any severe illness and had no extraordinary worries of any kind. The menses were regular in period but not in quantity. Her pulse was 60 , flabby and weak when at rest, but the least exertion or excitement made it irregular and fluttering. The temperature in the axilla was $97.5^{\circ} \mathrm{F}$. and in the mouth $97.7^{\circ}$. The heart sounds were feeble; the second sound was very sharp. A pulmonic systolic murmur could be distinctly heard and a loud blowing under the left clavicle. The urine was small in quantity, of specific gravity 1012 , with no traces of albumin or sugar. The abdomen was very much enlarged, hard, and tense, and a little tenderness on pressure was felt in the left hypogastric space. The spleen could be felt extending quite across the abdomen, its upper border reaching under the ribs and its lower coming to within three inches of the pubic arch. The microscopic examination of the blood showed an enormous preponderance of the white corpuscles and an abnormally small quantity of the red and white taken together. Many of the red appearing in the field seemed to be undergoing degeneration, many were granulated, while others had a broken and irregular contour. The patient liced in rather close and dark rooms. She suffered from headaches and constipation a good deal, seemed to have lost all hope of recorery, and was in a very despondent condition. There could be little doubt that the woman was suffering from leucocythæmia, though the sex and history of her case were somewhat unusual. She presented in a marked degree the dulled and enfeebled intellect so common to all affections of the blood. Indeed, I have noticed in a large number of anæmic cases that depression, lassitude, slowness of thought, and disinclination to mental work are amongst the earliest symptoms noticeable, appearing long before any pallor of the mucous membranes can be detected and even before there is any recognisable change in the appearance of the blood under the microscope. In nine cases out of ten such a train of symptoms will be found to precede disorders of the blood of an anmic character.

The small quantity of iron in the body in health and the very minute deficiency in what we call anæmia, the rapid but too often short-lived effect of the administration of the metal, would seem to suggest that we have in these cases to treat an affection of which the porerty of the blood is only a symptom and not a cause. It has been proved by Bequerel that where two fluids are separated by an animal septum they form an electrical couplet in which the surfaces of the septum form the positive and negative poles, consequently that the tissue cells act as galvanic batteries, from which, according to the nature of the surrounding fluids, a certain amount of electrical action results. It has been found that the internal and external surfaces of the capillaries act very markedly in this manner, while the peculiar distribution of the axis cylinders of the nerve fibres around the capillary walls would suggest the idea that at 